
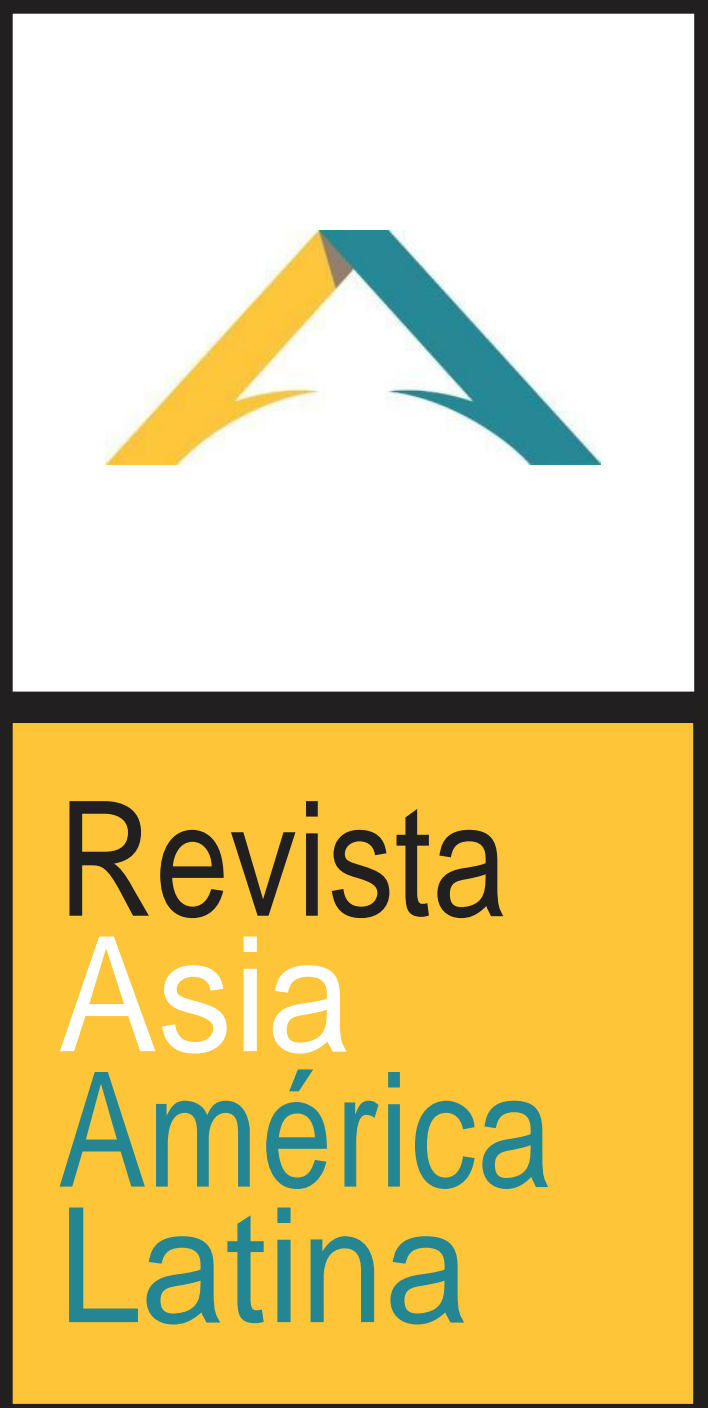

ISSN 2524-9347

Grupo de Estudios sobre Asia y América Latina Instituto de Estudios de América Latina y el Caribe Universidad de Buenos Aires

EU

DE BA 
Southeast Asia's Troubling Elections: Is There a Silver Lining?

Mark R. Thompson, Journal of Democracy, Volumen 30, Número 4, octubre de 2019, pp. 149-157 (Artículo) Publicado por Johns Hopkins University Press DOI: $10.1353 /$ jod.2019.0058

\section{COMICIOS INQUIETANTES EN EL SUDESTE ASIÁTICO: ¿HAY UN LADO POSITIVO?*}

En la primera mitad de 2019, tres países claves del Sudeste Asiático realizaron sus comicios: Tailandia celebró una votación parlamentaria en marzo; Indonesia tuvo elecciones presidenciales, legislativas y locales en abril; y Filipinas llevó adelante comicios legislativos de medio término, y una gran cantidad de votaciones locales en mayo.

Las noticias sobre estas elecciones son inquietantes. Las perspectivas democráticas en la región ya eran sombrías, y los resultados de estas votaciones podrían empeorarlas: en cada uno de estos tres países, una forma de gobierno autoritaria $-\mathrm{O}$, por lo menos, cada vez más iliberal- parece estar consolidándose. En Tailandia, las fuerzas pro establishment reunidas alrededor de la monarquía se esforzaron por poner una cara civil en lo que todavía es esencialmente un gobierno militar, "ganando" las elecciones en un proceso diseñado para perjudicar a los opositores.

En Indonesia, el presidente en ejercicio Joko Widodo (conocido como Jokowi) derrotó por segunda vez al intolerante populista Prabowo Subianto, pero el precio fue alto: hubo concesiones a los nacionalistas de línea dura, y a los islamistas que han atacado a minorías religiosas y sexuales. De todos modos, la administración de Jokowi ya se había estado moviendo en una dirección iliberal, y esas concesiones intensificaron dicha tendencia.

En Filipinas, los candidatos apoyados por el presidente Rodrigo Duterte dominaron las elecciones de medio término, permitiéndole avanzar en su agenda legislativa punitivista, mientras también intensifica el hostigamiento sobre sus oponentes. El índice de aprobación de Duterte es de alrededor del 80 por ciento, a pesar de $-\mathrm{O}$, más probablemente, debido a- su sangrienta "guerra contra las drogas". Esta violenta campaña populista, emprendida por agentes de policía que actúan como "justicieros", se ha cobrado miles de vidas.

¿Hay alguna esperanza para la democracia? Podría haberla. En Tailandia surgió una amplia coalición social para enfrentar al gobierno militar, y la junta gobernante tuvo que recurrir a la manipulación electoral y a elaborar una constitución fraudulenta para mantenerse en el poder.

\footnotetext{
*Traducción desde el inglés hecha por Fernando Pedrosa y Max Povse
} 
Indonesia mostró una reacción pluralista contra el extremismo cuando los votantes reafirmaron tanto la identidad islámica tradicional como la ideología nacional establecida en la Pancasila (cuyo origen se remonta a los albores de la independencia, a fines de la década de 1940). Como explican Edward Aspinall y Marcus Mietzner, Jokowi no es un modelo de político liberal-democrático, pero ha mantenido bajo control al extremismo islamista.

Mientras tanto, en Filipinas, los candidatos al Senado de la oposición fueron derrotados, pero impusieron un problema (la disputa territorial con China) que continúa atormentando a la administración de Duterte, incluso mientras lucha por conducir una coalición gobernante dilatada y fragmentada. Es probable que Duterte deje el cargo cuando termine su mandato en 2022, y existe la posibilidad de que puedan aparecer alternativas más liberales una vez que el actual presidente se retire.

Indonesia. Los resultados electorales del país más grande del Sudeste Asiático parecen ser los más positivos debido a que Prabowo perdió, y por casi el doble de votos que en las elecciones de 2014. Como un resabio de los años de Suharto (de quien Prabowo había sido yerno, además de un general acusado de abusos contra los derechos humanos), Jokowi fue acusado de "criptocomunista".

Prabowo fue respaldado por extremistas islamistas que actuaron en forma intimidante en pueblos y villas, y difamaron a Jokowi a través de Internet. Cada candidato atrajo la misma base de electores que tenía en 2014, con Jokowi siendo el más popular en el corazón de Java y en las áreas en el este de Indonesia, donde predominan algunos grupos minoritarios, mientras que Prabowo se impuso en las provincias musulmanas más conservadoras.

Cinco años en el poder demostraron que Jokowi no es un demócrata liberal, ya que trató de dividir a la oposición cooptando a una parte de los islamistas. La ocasión para el "giro autoritario" de Jokowi llegó a la mitad de su mandato, cuando los islamistas que permanecieron implacablemente en la oposición organizaron protestas masivas por acusaciones de blasfemia contra el sucesor de Jokowi como gobernador de Yakarta, por las que fue condenado en 2017. El objetivo real de las protestas, por supuesto, era Jokowi.

Desafortunadamente, Jokowi optó por luchar contra el autoritarismo de la oposición con su propio autoritarismo. Al mismo tiempo, el presidente hizo poco para proteger las libertades civiles a medida que aumentaron los ataques contra la comunidad LGBT y las minorías religiosas.

La amenaza a los derechos de las minorías por parte de islamistas y nacionalistas por igual muestra la retirada del "cosmopolitismo democrático" y 
el surgimiento de un "nacionalismo religioso" en Indonesia. ${ }^{\dagger}$ A medida que avanza la islamización y la intolerancia se normaliza, la era relativamente liberal de la reformasi iniciada con la caída de Suharto en 1998 parece ser cada vez más un mundo perdido.

Incluso cuando Jokowi decepcionó a sus partidarios liberales con su débil defensa de las libertades civiles, y con la elección de un islámico conservador como compañero de fórmula para las elecciones de 2019, las elecciones produjeron una suerte de efecto pluralista. Los votantes de mentalidad liberal dejaron de lado los planes para boicotear las elecciones cuando se dieron cuenta de que "cualquier esperanza de una sociedad más democrática había sido puesta sobre los hombros de Joko"¥.

La coalición de Jokowi, a pesar de adoptar un tono más islámico, contrarrestó la intolerancia de Prabowo al afirmar que representan a los musulmanes moderados y a las minorías no musulmanas de Indonesia.

La decisión de Jokowi de seleccionar como número dos de la fórmula al jefe de la organización tradicionalista sunita Nahdlatul Ulama (NU) resultó crucial. Además de ser el líder de NU, Ma’ruf Amin presidió el Consejo Ulama de Indonesia, el organismo a cargo de emitir fallos islámicos respaldado por el Estado. Ma'ruf Amin afirmó haber moderado sus posturas de línea dura, incluyendo su respaldo a los cargos presentados en el caso de blasfemia antes mencionado. Después de haberse dividido en 2014, NU se agrupó detrás de Jokowi y Amin en 2019. Fue una victoria para la identidad islámica tradicional y la Pancasila, ya que sus defensores habían afirmado que Prabowo tenía la intención de acabar con la República de Indonesia y hacer del país parte de un califato.

Tailandia. Durante casi dos décadas, la vida política tailandesa ha estado polarizada. Por un lado, están los partidos y movimientos sociales (los camisas rojas) que respaldaban al polémico ex primer ministro Thaksin Shinawatra. Por

\footnotetext{
'Thomas P. Power, "Jokowi's Authoritarian Turn and Indonesia's Democratic Decline,” Bulletin of Indonesian Economic Studies 54, no. 3 (2018): 307-38; Vedi R.Hadiz, "Indonesia's Year of Democratic Setbacks: Towards a New Phase of Deepening Illiberalism?” Bulletin of Indonesian Economic Studies 53, no. 3 (2017): 261-78; David M. Bourchier, "Two Decades of Ideological Contestation in Indonesia: From Democratic Cosmopolitanism to Religious Nationalism," Journal of Contemporary Asia (published online 8 April 2019): https:/ / doi.org/10.1080/00472336.2019.1590620. ${ }^{\ddagger}$ Eka Kurniawan, Indonesia’s Next Election Is in April. The Islamists Have Already Won, New York Times, 14 February 2019.

§Greg Fealy, "Ma'ruf Amin: Jokowi’s Islamic Defender or Deadweight?" New Mandala, 28 August 2018, www.newmandala.org/maruf-amin-jokowis-islamicdefenderdeadweight.
} 
otro lado, los sectores más tradicionales y sus representantes (establishment) se reunieron alrededor de la "red monárquica".** Estos grupos estaban representados por el movimiento de los "camisas amarillas", cuyas movilizaciones jugaron un papel importante en los golpes de Estado de 2006 y 2014, así como en la intervención indirecta de los militares en 2008.

Las bases de apoyo político de Thaksin se compone de los votantes urbanos más pobres, así como de personas que habitaban en el norte y noreste del país. A pesar que Thaksin ha estado en el exilio durante mucho tiempo, la agudización de las desigualdades entre clases y regiones ha continuado alimentando el movimiento populista asociado con él.

Entre 2001 y 2014, los grupos afines a Thaksin ganaron seis elecciones, dos de las cuales fueron anuladas. Sus oponentes de la élite no podían ganar en las urnas, por lo que aprendieron que, realizando una maniobra de dos pasos insurrección civil, seguida de intervención militar-, lograban mantener a Thaksin y sus sucedáneos fuera del poder.

La junta que asumió el poder en mayo de 2014 pospuso repetidamente las elecciones mientras buscaba implementar "reformas" que apuntaban a diluir los votos a favor de Thaksin y otorgar poderes de veto a los militares. Duncan McCargo explica que las dilaciones estratégicas de los militares mostraron cuán en serio el establishment del país tomó el desafío populista "a favor de los pobres" de Thaksin. Pero los esfuerzos -aparentemente exitosos- para marginar del poder a las fuerzas pro-Thaksin llevaron irónicamente a sus adversarios en el poder a aceptar las elecciones que alguna vez habían despreciado.

Para "ganar" las elecciones de marzo de 2019, el partido que representó al poder de los militares (Palang Pracharath) tuvo que apelar a múltiples manipulaciones. La Constitución de 2017 estuvo fuertemente sesgada a su favor. El clientelismo, el gerrymandering, las restricciones a los partidos rivales, el acoso a los activistas de la oposición y el fraude también fueron evidentes.

La comisión electoral incluso esperó hasta que se completara la votación para después cambiar la fórmula que distribuía los escaños entre los diferentes partidos políticos, nuevamente con el objetivo de ayudar al partido militar. Fue una elección "ineptamente manipulada", la "más sucia en décadas", y provocó

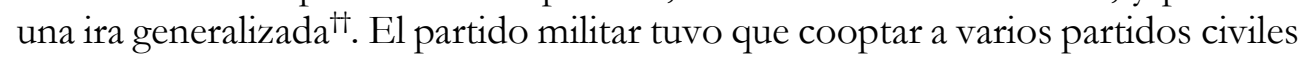
más pequeños para asegurar una mayoría oficialista estable.

\footnotetext{
${ }^{* *}$ Nota de los traductores: se entiende por "network monarchy" la estrategia llevadaadelante por el rey Bhumibol Adulyadej para crear una red a nivel nacional que responda a sus intereses políticos y dinásticos. Para profundizar ver https://www.tandfonline.com/doi/abs/10.1080/09512740500338937 +† "After an Ineptly Rigged Election, Thailand's Junta Will Cling to Power," Economist, 28 March 2019.
} 
Los votantes castigaron al partido más antiguo de Tailandia, los Demócratas, por sus vacilaciones frente al juego de poder de los militares. Como describe McCargo, los Demócratas no obtuvieron ni una sola banca en Bangkok, su bastión tradicional, y se han convertido en un partido regional, con sus apoyos reducidos al sur de Tailandia.

Después de las elecciones, los Demócratas se aliaron con el gobierno liderado por los militares. Esto provocó que su líder histórico renunciara, lo que sugiere la existencia de una división entre civiles y militares en las fuerzas antiThaksin. Los Demócratas que aun integran la Asamblea Nacional sienten presiones para demostrar que son independientes de los militares, y por ello han estado pidiendo reformas constitucionales.

El nuevo partido Future Forward, dedicado a oponerse a la participación de los militares en la política, obtuvo un fuerte apoyo en los votantes urbanos acaudalados y entre los jóvenes. Future Forward sorprendió a los observadores al convertirse en el tercer partido más grande del parlamento, prometiendo restaurar el gobierno democrático civil, incluso si eso implicaba hacer una causa común con las antes despreciadas fuerzas de Thaksin. Al ver a Future Forward como una gran amenaza, los sectores conservadores hicieron que el líder del partido fuera suspendido del parlamento con cargos de dudosa transparencia, y amenazaron al partido mismo con su disolución

A pesar de todo, Future Forward continúa exigiendo cambios constitucionales que eliminen las ventajas que los militares han diseñado para sí mismos, y apuntan a un camino que implique el regreso a un gobierno civil.

Para Prajak Kongkirati, un politólogo residente en Bangkok, los resultados de las elecciones han establecido que la división principal en Tailandia ya no sobre si se está a favor o en contra de Thaksin, sino a favor o en contra de la continua dominación de la vida política por parte de los militares. Las elecciones mostraron que el autoritarismo militar y las fuerzas pro-Thaksin retienen apoyos, pero no los suficientes como para evitar la reaparición de la división entre militares y civiles que había prevalecido en la política tailandesa hasta principios de la década de $1990^{\S \S}$.

\footnotetext{
${ }^{\ddagger \ddagger}$ Nota de los traductores: el partido fue finalmente disuelto y una veintena de sus dirigentes, entre ellos su líder Thanathorn Juangroongruangkit, imposibilitados de participar en la política nacional por una década.

$\$ \S$ See Prajak Kongkirati's contribution to the section on “Thailand's Amazing 24 March 2019 Elections" in Contemporary Southeast Asia 41 (August 2019). See also Napisa Waitoolkiat and Paul Chambers, "Battlefield Transformed: Deciphering Thailand's Divisive 2019 Poll in Bangkok," Thai Data Points, 7 June 2019, wmw.thaidatapoints.com/post/battlefield-transformed-deciphering-thailand-s-divisive-2019-poll-inbangkok.
} 
Los militares tailandeses, con el respaldo de la monarquía, han erigido un autoritarismo electoral. Pero esa fue la parte fácil. La parte difícil será buscarle una apariencia civil y parlamentaria estable y convincente para enmascarar el control militar. Las fuerzas armadas tailandesas tienen un historial claramente pobre al respecto. Las elecciones de marzo de 2019 "no lograron inducir [la] obediencia política" buscada por el sector conservador militar-monárquico: las elecciones mostraron que los votantes son subversivos, como a menudo lo han sido en la historia reciente del Sudeste Asiático ${ }^{* * *}$.

Filipinas. Aunque no estaba en la boleta electoral, no hay duda de que las elecciones parciales de Filipinas en mayo de 2019 favorecieron a Duterte. Las acusaciones de violaciones masivas de los derechos humanos asociadas con su sangrienta "guerra contra las drogas" han fallado en reducir su popularidad estratosférica. Los votantes ven que su violento líder gobierna como es necesario para reformar y establecer el orden en un país donde las instituciones clave son débiles y disfuncionales ${ }^{\text {ttt }}$.

Para demostrar una voluntad política inquebrantable, Duterte utiliza regularmente lo que Denise van der Kamp, una politóloga de Hong Kong, denomina como "regulación a través de fuerza contundente", no solo en busca de delincuentes, sino que la aplica arbitrariamente para clausurar cosas en todos los ámbitos.

En abril de 2018, por ejemplo, cerró por completo la isla de Boracay durante seis meses, un importante destino de vacaciones internacionales, para facilitar tareas de limpieza y renovación de la infraestructura. A fines de julio de 2019 ordenó abruptamente que la Oficina de Sorteos de Caridad de Filipinas y

\footnotetext{
*** Prajak Kongkirati, "Why Thailand's Generals Fail to Co-opt Elections," New Mandala,15 January 2019, www.newmandala.org/why-thailands-generals-fail-to-co-opt-elections; Mark R. Thompson, "Southeast Asia's Subversive Voters: A Philippine Perspective," Philippine Studies 64 (June 2016): 265-87; Kasian Tejapira, "Elite Realignment, a Populist Moment: Reflections on Thailand's 2019 General Elections," New Mandala, 4 April 2019, www.newmandala.org/elite-realignment-a-populist-moment-reflections-onthailands2019-general-elections.

${ }^{++\dagger}$ Mark R. Thompson, "Why Duterte Remains So Popular: The Failures of the Philippines’ Liberal Reformism,” Foreign Affairs, 9 October 2018, www.foreignaffairs.com/articles/philippines/2018-10-09/why-duterte-remains-sopopular. Nearly four in five Filipinos fear that they or someone they know may become a victim of extrajudicial killings, which indicates the ambiguous attitude of many Filipinos toward the violent "drug war." See Consuelo Marquez, "SWS: Most Filipinos Fear Being Victimized by EJK," Philippine Daily Inquirer, 1 March 2019, https://newsinfo.inquirer.net/1091192/sws-most-Filipinos-fear-being-victimized-byejk/amp
} 
su Lotería de Pueblos Pequeños cesaran sus operaciones luego de denuncias de corrupción.

$\mathrm{Ni}$ un solo candidato de la oposición salió victorioso en las elecciones de mitad de período en el Senado, la primera vez desde 1938 que esto ha sucedido. $\mathrm{Al}$ igual que los presidentes anteriores, Duterte ganó fácilmente el control de la cámara baja mediante el uso del clientelismo.

La Corte Suprema se comportó dócilmente cuando su presidente fue removido mediante una maniobra legal nefasta, y otros jueces se retiraron al alcanzar la edad de jubilación.

Con el encarcelamiento o destitución de opositores clave, y ataques "nacionalistas resurgentes" contra "intrusos extranjeros" y sus "lacayos domésticos", las organizaciones de la sociedad civil no han podido sostener las protestas antigubernamentales. Después de las derrotas en las elecciones del Senado de 2019, no queda ningún bastión de la oposición que se interponga en el camino de Duterte

Como Björn Dressel y Cristina Regina Bonoan señalan en su contribución a este tema, el presidente ya ha avanzado mucho en el desmantelamiento de los controles constitucionales "por medios nominalmente legales". Ahora, sus partidarios del Senado están en posición de cambiar la Constitución de 1987 (bajo la apariencia de reemplazar el sistema unitario de Filipinas por uno federal). El Senado probablemente también lo ayudará a restablecer la pena de muerte, que Duterte quiere reimponer como parte de su campaña de represión contra las drogas.

En cuanto a las investigaciones de alto perfil del Senado sobre Duterte y su familia, esas parecen ser cosas del pasado. Duterte ha apuntado durante mucho tiempo contra los medios independientes y otras voces críticas, pero poco después de las elecciones su acoso a los críticos alcanzó un nuevo máximo: el presidente presentó cargos de subversión contra la vicepresidente (en Filipinas, es un funcionario elegido por separado) y casi tres docenas de otros opositores, incluidos senadores y candidatos, activistas de derechos humanos, académicos y cuatro obispos católicos. Las ejecuciones extrajudiciales de activistas de izquierda han crecido recientemente: solo en la provincia de Negros Oriental, veinte de ellos fueron asesinados a tiros en una sola semana a fines de julio.

Filipinas tenía un sistema hiperpresidencial antes de que Duterte asumiera el cargo, pero él ha transgredido incluso los pocos límites que

\footnotetext{
¥¥¥ Julio C. Teehankee, “Duterte’s Resurgent Nationalism in the Philippines: A Discursive Institutionalist Analysis", Journal of Current Southeast Asian Affairs 35 (December 2016): 69-89. Paul Hutchcroft, "Midterm Elections Deepen Duterte's Domination," East Asia Forum, 2 June 2019, www.eastasiaforum.org/2019/06/02/midterm-elections-deepen-dutertes-domination
} 
permanecían sobre el poder ejecutivo. Ahora es la figura política individual más poderosa que el país ha visto desde que el dictador-presidente Ferdinand Marcos fuera expulsado de su cargo en 1986.

Pero en cierto sentido, Duterte se ha convertido en una víctima de su propio éxito. Su tsunami electoral dejó una coalición de gran tamaño que ha comenzado a dividirse cuando el presidente ingresa a la segunda mitad de su mandato de seis años. En su clásico The Theory of Political Coalitions, de 1962, el politólogo estadounidense William H. Riker planteó la idea de la "coalición ganadora mínima". Riker sostuvo que los líderes reunirán tantos aliados como necesiten para gobernar, pero no tanto como para que los recursos deben repartirse más de lo necesario.

Cuanto más grande es una coalición, es más probable que sea menos duradera. Ganar elecciones por un margen que es "demasiado grande" significa -en otras palabras- tener que satisfacer a demasiados seguidores. Hay clanes y facciones políticas rivales en el terreno político de Duterte. Compitieron abiertamente entre sí durante las elecciones de medio término. Duterte no priorizó la "movilización sistemática de clientelismo" para promover la unidad de sus partidarios durante la campaña, sino que confió en su propia y popular narrativa política como líder fuerte del país sss.

Después de las elecciones estalló una batalla por la presidencia de la Cámara de Representantes. Duterte se vio obligado a llevar a cabo una intervención personal sin precedentes, negociando un acuerdo con el fin de lograr un débil equilibrio en la cámara baja. Nada de esto es un buen augurio para quien sea que Duterte elija respaldar como su sucesor.

Los presidentes filipinos generalmente no han logrado decidir quién vendrá después de ellos en el cargo. El último jefe del Poder Ejecutivo en lograr esa hazaña fue Corazón Aquino, la primera presidente post-Marcos. En 1991, ella recomendó a su ministro de defensa, Fidel V. Ramos, para el cargo más alto del país. Ramos consiguió por poco la victoria en 1992, ganando con menos de un cuarto de los votos en una elección de seis candidatos.

Se cree que Sara Duterte, que, como su padre antes que ella, es la alcaldesa de la ciudad de Davao en Mindanao, será elegida como su sucesora. Sin embargo, la presentación de la joven de 41 años al público de todo el país durante la campaña de 2019 estuvo lejos de ser perfecta, y la historia tampoco es favorable a que se convierta en presidenta.

Como lo reveló el conflicto en la Cámara de Representantes, la lucha de poder entre las diferentes facciones ya está muy agitada, y aumentará a medida que se acerquen las elecciones presidenciales de 2022. Esto podría promover una

§§ Julio C. Teehankee and Yuko Kasuya, "The Philippine Midterms and the New 'Presidential Bandwagon,"' New Mandala, 28 May 2019, www.newmandala.org/thephil-ippine-midterms-and-the-new-presidential-bandwagon 
competencia abierta, ya que ninguna facción parece lo suficientemente fuerte como para vencer y todos, por lo tanto, sienten cierto interés en mantener la escena política relativamente nivelada mientras compiten por los votos. También es posible que algunos candidatos que buscan suceder a Duterte intenten destacarse prometiendo poner fin a sus abusos de poder.

Esto es más probable si el discurso político de Duterte se debilita. Su imagen como un tipo duro (siga), aparentemente intocable en el país, parece amenazada por los movimientos agresivos de China en el Mar de China Meridional, y por el aumento de la inmigración china a Filipinas.

Durante las elecciones de medio término, la oposición criticó la debilidad de Duterte en contrarrestar el avance de China sobre las islas, y denunciaron que los proyectos de infraestructura financiados por China podrían afectar la deuda de Filipinas.

La afluencia hacia Filipinas de más de150.000 trabajadores chinos, muchos de ellos como personal de la industria de los juegos online, también ha generado preocupaciones. El 9 de junio de 2019, poco después de las elecciones, un barco chino con casco de acero embistió y hundió un barco pesquero de madera filipino en el Mar de China Meridional, y luego siguió su camino. Recién cuando dos de los 22 miembros de la tripulación filipina lograron llegar a un barco pesquero vietnamita, la tripulación fue rescatada.

El intento de Duterte de minimizar la embestida como "un pequeño accidente marítimo" fue refutado por la misma Guardia Costera de Filipinas. Duterte luego reconoció que, en forma secreta, había permitido a los chinos pescar en aguas que, el Tribunal Permanente de Arbitraje de La Haya así había dictaminado en 2016, quedan dentro de la Zona Económica Exclusiva de Filipinas. Duterte afirmó que había hecho ese acuerdo porque era la única forma de evitar una guerra con China.

Por esto no es sorprendente que cada vez más filipinos expreses opiniones negativas sobre su enorme vecino en las encuestas de opinión. La sensación de que Beijing se está aprovechando de un presidente que carece de la voluntad de proteger los intereses de Filipinas podría dañar a Duterte en el futuro a pesar de su popularidad actual.

Curiosamente, aparte de los opositores políticos, el crítico más destacado de Duterte en este asunto ha sido el juez de la Corte Suprema, Antonio Carpio. Designado en la corte por la expresidenta Gloria Macapagal-Arroyo, ahora una aliada cercana de Duterte, Carpio denuncia el "gran robo" de China de los derechos marítimos filipinos en el "Mar de Filipinas Occidental".

Las presidencias filipinas más recientes comenzaron con una explosión, pero terminaron con un sollozo. El predecesor de Duterte, Benigno "Noynoy" Aquino III, asumió el cargo prometiendo un "camino directo" hacia un gobierno honesto, pero la suma de escándalos llevó su presidencia a un punto muerto. La guerra contra las drogas de Duterte, con su violencia estatal sistemática, es objeto 
de investigación por la Corte Penal Internacional (a pesar que Duterte retiró a Filipinas de ella). Su política antidrogas también es objeto de una investigación realizada por el Consejo de Derechos Humanos de la ONU, lo que sugiere que es un problema que no desaparecerá fácilmente.

A medida que las preguntas sobre la política de China persiguen al presidente, $\mathrm{y}$ mientras las facciones que integran su gran coalición compitan para sucederlo, los reclamos por cambios en la política exterior -e incluso por la salvaguarda de los derechos humanos- pueden contribuir a aumentar el pluralismo político.

\section{El dilema del dictador}

Que las elecciones sean una pequeña posibilidad de crear un entorno democrático no es inusual en contextos iliberales. Incluso cuando los gobiernos se han quedado cortos en su adhesión a las normas democráticas, como fue el caso de Jokowi en Indonesia durante su primer mandato, puede darse una vuelta al pluralismo. En el curso de la campaña de 2019, las fuerzas pro-Jokowi desmovilizaron a los extremistas y lograron convertir el voto en una reafirmación mayoritaria de la identidad islámica tradicional y la ideología nacional de la Pancasila.

Las elecciones a menudo se han utilizado para legitimar el iliberalismo o el autoritarismo electoral ${ }^{* * *}$. Los regímenes autoritarios utilizan las elecciones para dar una apariencia democrática, incluso cuando su sustancia se ve socavada, ya sea por la manipulación directa o por límites a la libertad y a la participación que producen que las elecciones no sean justas.

Pero los dictadores se enfrentan a un dilema: las elecciones - a veces incluso las que no son libres, pero especialmente las que son "solo" injustastienen una lógica propia. En Malasia, en 2018, el partido que gobernaba desde hacía mucho tiempo inclinó el campo a su favor, pero aun así sufrió una sorprendente derrota en las urnas. Las elecciones robadas pueden conducir a la movilización revolucionaria y al derrocamiento del régimen, como sucedió en Filipinas en $1986^{\mathrm{HtH}}$.

\footnotetext{
**** Andreas Schedler, ed., Electoral Authoritarianism: The Dynamics of Unfree Competition (Boulder, Colo.: Lynne Rienner, 2006); Steven Levitsky and Lucan A. Way, "The Rise of Competitive Authoritarianism," Journal of Democracy 13 (April 2002): 51-65

${ }^{++++}$Samuel P. Huntington, The Third Wave: Democratization in the Late Twentieth Century (Norman: University of Oklahoma Press, 1991), 174-91; Philipp Kuntz and Mark R. Thompson, "More than the Final Straw: Stolen Elections as Revolutionary Triggers,” Comparative Politics 41 (April 2009): 253-72.
} 
Pero incluso si un partido gobernante iliberal "gana" las elecciones, recurrir a "ventajas injustas" para hacerlo puede disminuir su legitimidad. Esa ha sido la historia en Tailandia en 2019. En la medida en que las campañas electorales permitan la emisión de críticas antigubernamentales, estas pueden activar divisiones latentes desfavorables para el iliberalismo.

En Tailandia, los cinco años de gobierno militar transcurridos entre el golpe de Estado de 2014 y la votación de 2019 llevaron a más ciudadanos a aceptar la idea de que los militares deberían retirarse de la política. Para dar voz a esta idea se formó un nuevo partido y entró en una coalición con los populistas pro-Thaksin, a quienes las clases medias tailandesas solían despreciar. Esto dejó al partido proxy del ejército luchando por aferrarse a sus propios socios de la coalición, quienes pueden percibir la tendencia social antimilitar, y se dan cuenta de que les conviene convencer a los votantes de que ellos también están comprometidos con una mayor autoridad civil.

Finalmente, los festejos de una victoria electoral iliberal pueden perder su brillo si, como está sucediendo ahora en Filipinas, una coalición ganadora de gran tamaño genera luchas internas: un colectivo de vencedores que se codean entre sí mientras compiten por tomar el botín y posicionarse de la manera más favorable para las próximas elecciones.

Un apoyo feliz para la democracia puede ser el interés egoísta ampliamente compartido de mantener competitivas las elecciones. Las puertas hacia un mayor pluralismo, además, pueden aparecer cuando temas controvertidos (problemas marítimos con China en Filipinas, por ejemplo) se convierten en tierra fértil para futuras demandas en campaña.

En resumen, los sistemas autoritarios tienen grietas, y la democracia a veces puede entrar a través de ellas. 

